\title{
Posterior Inferior Cerebellar Artery
}

National Cancer Institute

\section{Source}

National Cancer Institute. Posterior Inferior Cerebellar Artery. NCI Thesaurus. Code C33362.

An artery arising from the vertebral artery that supplies the cerebellum, choroid plexus and the lateral medulla. 